\title{
A critique of Bernstein's beyond objectivism and relativism: science, hermeneutics, and praxis
}

\author{
Jonathan Matusitz • Eric Kramer
}

Published online: 29 April 2011

(C) Springer-Verlag 2011

\begin{abstract}
This analysis comments on Bernstein's lack of clear understanding of subjectivity, based on his book, Beyond Objectivism and Relativism: Science, Hermeneutics, and Praxis. Bernstein limits his interpretation of subjectivity to thinkers such as Gadamer and Habermas. The authors analyze the ideas of classic scholars such as Edmund Husserl and Friedrich Nietzsche. Husserl put forward his notion of transcendental subjectivity and phenomenological ramifications of the relationship between subjectivity and objectivity. Nietzsche referred to subjectivity as "perspectivism," the inescapable fact that any and all consciousnesses exist in space and time. Consciousness is fundamentally constituted of cultural, linguistic, and historical dimensions.
\end{abstract}

\section{Introduction}

This paper critiques Bernstein's view of subjectivity based on his book entitled Beyond Objectivism and Relativism: Science, Hermeneutics, and Praxis (1983). Bernstein tries to widen the context of subjectivity and claims that modern discussions to the foundations of science and human action must consider thinkers such as Gadamer and Habermas, who suggested that one cannot reach absolute truth because truth is subjective. One of the classic scholars referred to in this analysis is Husserl (1913/1982). Husserl based his notion on transcendental subjectivity. He established the historical rise and the phenomenological ramifications of the relationship between subjectivity and objectivity; more precisely, what he called the

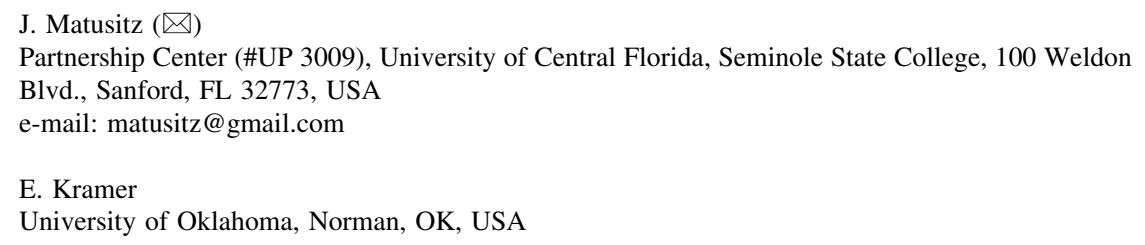


naturalistic versus the personalistic "attitudes." They come into existence together. Another classic scholar in this analysis is Nietzsche (1882/1974). The Cartesian obsession with calculation and mathematical objectivity gave rise to the realization of what Nietzsche called perspectivism, which is the inescapable fact that any and all consciousnesses exist in space and time; that consciousness is fundamentally constituted of cultural, linguistic, and historical dimensions. Each knowing subject is situated, and this is itself a universal fact.

What Bernstein calls the naïve notion of "objectivity" is what Husserl (1913/ 1982) called the thesis of the natural attitude, which is the untested belief that there exists some sort of permanent, ahistorical truth, or knowledge framework in the world "out there" (Rorty 1998). Another focus of this paper, then, is the analysis of the subjectivity of one type of knowledge: scientific knowledge. Scientific knowledge cannot be entirely objective because it only represents the intersubjective agreement of a community of scholars. It is created through "interpretation." Its postulates, methods, and conclusions are constantly open to the critical scrutiny by the scientific community. There is no method that can see and measure everything because each phenomenon has what Husserl calls a different ontological structure. Finally, this paper lays foundations for more research on the explanation of the role of subjectivity in science and absolutism.

\section{Subjectivity and relativism according to Bernstein}

In Beyond Objectivism and Relativism: Science, Hermeneutics, and Praxis (1983), Bernstein tries to widen the context of subjectivity and claims that modern discussions on the foundations of science and human action must consider thinkers such as Gadamer and Habermas, who put forward the idea that one cannot reach absolute truth because truth is subjective. Subjectivity is essentially self-awareness or self-consciousness. This statement is clearly illustrated by Bernstein's challenge of the existence of "a firm foundation, an ontological grounding, a fixed categorial schemes" (1983:9). Consequently, all scientific methods that are used can never be "flawless."

This modern idea of subjectivity originated with Descartes (Judowitz 1988). As discussed by Bernstein, the Cartesian tradition implies self-awareness, the idea that the human being is aware of his or her inner representations and that his or her mind infers the existence of a thinking subject from such awareness. Subjectivity, thus, is a direct result of the mind's ability to be aware of its own representations. This is particularly true in the social sciences, in which research is often criticized as being "subjective" and, thus, as not having much validity as research in the "hard" sciences. Subjectivity must mean that there are misrepresentations in the "reality" depicted by that knowledge. Those misrepresentations would be a function of the individual perspectives and value systems of the scientist. We go beyond objectivism, which makes Bernstein's conception of "praxis" (that is, the process by which something, i.e., a theory, becomes part of our lived experience) move toward the avoidance of both foundationalism and nihilism. Bernstein cannot accept 
the idea that absolutism or objectivism is true-his definition of "absolute" knowledge is based, partly, on the readings of Hegel (1807/1977).

According to Husserl (1900/1970), subjectivism is an ideology, a metaphysic that it is ontologically equal to objectivism. They are both isms as such. When he talks about subjectivity, he means the categorical phenomenon that is presumed for all experience "subjective" or "objective." It is confusing. Many have complained about his choice of the word subjective with regard to transcendental subjectivity, but there it is. Perhaps, "awareness" would have been better. We are aware of both subjectivity and objectivity, and, at the level of pure awareness, they are equal metaphysically and ontologically. Objectivity is a phenomenon just like subjectivity and it has no priority or privilege. Bernstein confuses transcendental subjectivity with mundane subjectivity.

This is a huge mistake by Bernstein. Husserl (1913/1982) is not a relativist at all. Husserl is saying that we all have a pure awareness (pure meaning prior to metaphysical judgments) and that, from this level of pure awareness, we experience both attitudes (objectivist and subjectivist) and that they have different meanings. As attitudes, they are identical. They are metaphysical prejudices that need to be bracketed so we can study phenomena without bias-be they logic, dreams, hunches, rocks, equations, or molecules. Some, we might protest, are not "real" objects like dreams and equations, but Husserl brackets this sort of metaphysics as the naïve natural attitude (read as "objectivism"). From this vantage point, subjectivity and objectivity are both metaphysical judgments and ideologies and they both arise together. We are aware of them in the same waytranscendental awareness. Once we bracket the metaphysical judgment, then we can step back, as it were and see them both for what they are: ideologies, perspectives, and judgments and then we can see them as identical. There are two sides of the same coin.

What is objectivism? It is an ism. What is subjectivism? It too is an ism. They are phenomena that share qualities, the qualities of being not things but ideologies. We can identify when and where they became important - the enlightenment, in parts of Western Europe. This obsession with metaphysical judgment turns out to not be shared by hardly any other culture. For magic peoples, for instance, spirits and dreams may be more real, more significant, than rocks and wood. So, this ideological conflict between subjectivity and objectivity turns out to be very ethnocentric, very much a child of the European enlightenment. This is why Gadamer (1989) turns against what he calls the enlightenment prejudice against prejudice as irrational. We cannot escape limitations.

Husserl (1900/1970) invented the method of phenomenological reduction and bracketing to avoid the absurdity of objectivists and material scientists denying the existence of mathematics and science. Science is not an object with bumps and polka dots. By bracketing metaphysical judgment, Husserl enables us to validly investigate all phenomena without prejudice, be they math (as in his own case) or rocks. Husserl also went on to establish the necessary conditions for objectivity: intersubjective agreement. Here, Husserl is speaking of subjectivity in its mundane sense, not as transcendental awareness. However, from the vantage of 
transcendental awareness, we are able to step back and investigate this process of communicating mundane subjects and how they do it.

We must investigate the necessary conditions for agreeing. Husserl says, it is transcendental linguisticality; that is, the human capacity for language, which is not limited to any one mundane subject and to synchronize through the process of convention on a code that enables meaning to be generated and shared. What enables this process of convention is communication itself and the rules of convening. Here, we are brushing up against Noam Chomsky and Martin Heidegger. Hence, the linguistic turn as the basis for explaining all phenomena which are public_-and maybe even private insofar as we think and feel in words $a$ la Isocrates, Sapir, and Whorf.

There is growing evidence that these scholars were right, that the physical brain is a sociocommunicative product and that the brain changes its physical structure as it acquires language, and that these neuronets constitute a specifically linguistic consciousness. That language here is not merely words and grammar but what Maurice Merleau-Ponty (1945/1962) suggested in his Phenomenology of Perception and Nietzsche even earlier: much more of the bandwidth of social interaction through touch, taste, and smell. In this respect, one can think of Small and Vorgan's (2008) iBrain, Ledoux's (2002) synaptic self, Schwartz and Begley's (2003) neuroplasticity, Doidge's (2007) brain that changes itself, Lakoff and Nuñez's (2001) origins of mathematics, and Lakoff and Johnson's (1999) philosophy in the flesh. Nietzsche (1882/1974) realizes that consciousness and language go hand in hand but that there is more to the story:

The development of language and the development of consciousness (not of reason but merely of the way reason enters consciousness) go hand in hand... [this is] the need to communicate [ideas] to others by means of signs. The human being inventing signs is at the same time the human being who becomes ever more keenly conscious of himself. It was only as a social animal that man acquired self-consciousness-which he is still in the process of doing, more and more... consciousness does not really belong to man's individual existence but rather to his social or herd nature. (354)

Here, Nietzsche originates a new way of thinking; he recognizes at once both the essential nature (the necessary condition for) consciousness as we know it-as linguisticality of Dasein (as Heidegger put it). Yet, Nietzsche also realizes that this is merely self-consciousness and that this involves the emergence of ego. As dimensions accrue, dissociation increases, which means that the ego slowly emerges from oceanic consciousness (to borrow from Freud) into collectivism toward increasing individualism. In the process, we talk more and more; idea's thinking becomes valorized more and more. The enlightenment is the age of ideology and modern ego. Bernstein (1990), Giles (1972), and Hall (1966) note how the more individualistic a culture, the more people in that culture talk-and the more verbal they become (i.e., elaborated code).

Nietzsche (1882/1974) notes in this short little passage, so jammed with insight, that a key objective of language, communication, and evermore precise language is a product of the desire for command-to give orders to others and for ordination in 
general. It is a will to power. Leaders are rhetoricians. Power in academe comes from publishing-words, words, words, from magic incantation to mental-rational formulation. More fragmentation leads to the power of precision-to impose one's will. So, we divide everything into more and more words, smaller measures (hours, minutes, and seconds; less tolerance in machining the world), and specialized vocabularies. In this manner, we can better conceptualize, categorize, and comprehend.

\section{The limitations of knowledge: intersubjective agreement, not objectivity}

Objectivity is the belief that there exists some sort of permanent, ahistorical truth, or knowledge framework. As Michael Crotty (1998) defines it,

Objectivity is the epistemological view that things exist as meaningful entities independently of consciousness and experience, that they have truth residing in them as objects ("objective" truth and meaning, therefore), and that careful (scientific?) research can attain that objective truth and meaning. (5)

Truth only exists in and out of our engagement with the realities in our world. Bernstein follows the lead of Gadamer when he claims that it is naïve to talk about a purely objective point of view. Objectivity is an untenable form of rationality. Now we understand it. Meaning cannot be objective because there is no meaning without a mind (Crotty 1998). Kant (1785/1981) argues that reality as we know it depends on the cognitive functioning of the human mind. Society determines what is true and false, right and wrong. This is the essence of Kant's social primacy of consciousness in metaphysics. What we think is true is a collective delusion from which no one can escape. Since the ideas of Kant, "objectivity" has generally been thought to mean collective subjectivism. There is no Truth. Søren Kierkegaard (1997) said that truth is subjectivity. It is then impossible to discuss, argue, or judge any one group's truth as more accurate or less correct than any other's. With no possibility to reason among the groups, the only alternatives are either ethnocentrism or intergroup comparison (e.g., social identity theory) through which political power is misused and abused to bash cultural differences.

The existence of a world without human minds is conceivable; yet, meaning without human minds is inconceivable (Guba and Lincoln 1994). Meaning stems from intersubjective agreement or intersubjective conceptions of objectivity (Gauker 1995). Habermas attacks the commonly held belief that knowledge is limited to empirically testable propositions reached through disinterested, valuefree inquiry, a notion that lies at the core of both positivism and objectivist rhetoric. Since people engage in consensual communication in order to achieve intersubjective agreement, they should not try to win an argument at any cost, but, instead, should listen to the other participants. As Habermas (1979) says, the goal of communication is to reach agreement. 


\section{The limitations of knowledge and scientific method}

As Gadamer (1989) realized the derogation of the "common sense" by the enlightenment philosophers is unwarranted. Cultures and subcultures, such as groups of astronomers, presume a conventional set of interests and presuppositions which form the basis of the patterns they "discover." As Nietzsche (1882/ 1974) pointed out, what is often called knowledge is really only that which is familiar to us personally, and after all, all direct observation, the basis of empirical data, is at origin, personal. Nietzsche identified the origin of the motive for knowledge in the desire for power and in our most fundamental fear of the unknown:

What do they want when they want 'knowledge'? Nothing more than this: something strange is to be reduced to something familiar... what is familiar means what we are used to so that we no longer marvel at it... something that no longer disturbs us. Is not the instinct of fear that bids us to know? And is the jubilation of those who attain knowledge not the jubilation over the restoration of a sense of security? (300)

Here, Nietzsche is anticipating by nearly a century the idea that for the modern human who no longer thrives on mysteries, the unknown generates anxiety which can only be allayed by making the unknown known. This is done through communication with the world, be it in what moderns call a methodical fashion or in a less managed way. In the end, it is about self-efficacy and power. Science, with its practical expression as technology, is hardly objective unless one counts the will to power, the will to confront and control natural forces, a mission without desire, will, direction, or purpose-in a word, human, all too human motivation. Again, Nietzsche (1882/1974) is instructive:

Do you really believe that the sciences would ever have originated and grown if the way had not been prepared by magicians, alchemists, astrologers, and witches whose promises and pretensions first had to create a thirst, a hunger, a taste for hidden and forbidden powers? (240)

Science insists upon questioning not only the subjects or events that we find in the world, but also our knowledge about the way the world is, and the way we come to know things about it. Science works because no knowledge is ever taken as being final. Rather, it is created through "interpretation" and is always ideational and provisional. It "is just a particular form of constructed knowledge designed to serve particular purposes" (Crotty 1998:16). Any method in the social sciences is limited in that it cannot deal with the unique, especially when it comes to analyzing human behavior. A scientific method attempts to find a pattern among things that are timeless, universal, dependable, and replicable. In fact, what is crucial to scientific method is experimental repeatability or reproducibility (Moore 1973). Yet, things that are unique or that do not fall into these categories are outside the realm of science. As Weisz (1965) puts it, "one-time events on earth are outside of science" (4). Moore (1973) adds that, 
the important distinction between science and those other systematizations (the arts, philosophy, and theology) is that science is self-testing and selfcorrecting. The testing and correcting are done by means of observations that can be repeated with essentially the same results by normal persons operating by the same methods and with the same approach. (23)

Giving another example, statistics cannot be applied to individual cases. It is a heuristic model designed with a view to ensuring that the results have certain preconceived properties. Therefore, the statistical model, and any scientific method, is preconceived, prejudiced, and biased, because it is humanly made. Plus, going back to the idea of repeatability, replication also has to do with claims to objectivity based on intersubjective agreement. There are well known epistemological problems with this. Equally important, despite a large number of observations and a large number of cases showing consistency generated through a method, it can never be guaranteed that the next event would not be contrary to it. Henceforth, repeated observation cannot ultimately explain induction. For example, no matter how many white swans we may have seen in our lifetime, it does not imply that all swans are white; the next that we see may be black (Popper 1992).

Finally, subjectivity may emerge when the variables measured are intangible. Intangible variables are variables that "are based on observations but that cannot be observed directly or indirectly" (Babbie 2001:121). These variables are known as constructs (Kaplan 1964). While constructs cannot be measured directly, there may be some questions about them being real, in the sense that they are directly observable and are constructed from measurements of other variables. They can be considered valid because, although not real or observable in themselves, "they have a definite relationship to things that are real and observable" (Babbie 2001:122).

A scientific method does not immunize us from ourselves, but, instead, it institutionalizes our prejudices. After all, a method is always designed by someone. There is no method that can see and measure everything because each phenomenon has what Husserl calls a different ontological structure. Ontology is the study of being; it is concerned with "what is" and the structure of reality as such (Crotty 1998). In other words, their mode of being varies. The structure (called sinn in German) of meaning cannot be entirely taken by reflecting on the contexts within which meanings appear. They have to be understood in the structure of the being. Ontological structure is important in the social sciences because the human being is, ontologically, a "being there." As such, he or she is not merely a being like all the other beings in the world, but a being that has a relation with his or her own being. Bernstein (1983) states that Husserl's explication of the ontological structure of the world leads us to transcendental intersubjectivity. Transcendental intersubjectivity enables comparison among things. As Husserl (1900/1970) explains it,

within the vitally flowing intentionality in which the life of an ego-subject consists, every other ego is intentionally implied, "implied" of course not as real particular persons in the flesh but as others in general, that is, as a "transcendental intersubjectivity." (255) 
Science is a dialectical process, which functions through coevolution and intersubjective agreement. In order to reach that agreement, a language game is needed because, as Wittgenstein (1965) puts it, language does not only describe events but also creates a cosmology, a view of the world that influences the thought, behavior, and perception of humankind. We speak about our observation of the world, more so than about the world itself (Baker 1991). Method is merely a language game. We do this through a language game. Edward Sapir (quoted in Whorf 1962) corroborates the argument in favor of the importance of language in scientific method. He puts forward the idea that humans do not live in the objective world alone, nor alone in the world of social activity as we know it. On the contrary, humans are deeply at the mercy of their particular language, the medium of expression of their society. Sapir thinks it is naïve to believe that one can adjust to reality essentially without language and that language is just a subordinate means of solving specific problems of communication or reflection.

\section{Final notes on objectivism versus subjectivism}

We might suggest the application of Bakhtin's (1930/1981) notion of chronotope, a spatiotemporal complex that characterizes every genre of writing, to all human experience. Originally, the concept was borrowed from Einstein's work on relativity and applied to biology. Then, Bahktin applied it to novels, and we now can recognize its affectivity for all human experience. The explosion of Cartesianism (metaphysical duality) comes with the realization that it is an "objective" fact that observation is always from a particular perspective. This is living the aporia of human existence, which Kramer (1997) calls "relative relativism," that is, the development of a typology of different worldviews based on the work of Jean Gebser (1985) that would limit absolute relativism and enhance our ability to speak meaningfully of generalizable difference across cultures and civilizations. Like a double negative, relative relativism limits interpretations for practical purposes. The motive for this move is that the realization that absolute relativism is the ultimate threat to praxis.

Absolute objectivity is a child of the age of ideology, a version of utopian thinking born of the positivistic movement in France during the eighteenth century. It is, ultimately, naively optimistic. Why naïve? Nietzsche demonstrates that perspectivism, the objective fact of perspectivism, is not negativism, if one associates negativism with nihilism. Nietzsche argues that, quite the contrary, positivism, with its demand that only my perspective is real and no other alternatives can or should be considered, is nihilistic. Because positivism demanded absolute epistemic domination for its one true version of reality, Nietzsche (1882/ 1974) responds, "A 'scientific' interpretation of the world, as you understand it, might therefore still be one of the most stupid of all possible interpretations of the world, meaning that it would be one of the poorest in meaning" (p. 335). Notice here that Nietzsche is explicitly stating that a scientific or objectivist picture of the world is merely one interpretation among an infinite number of possible interpretations and that it is among the most impoverished because science, as a 
prejudice, refuses a priori to grant any validity to any other version of reality. It is, in short, the very definition of prejudice.

Thus, it is not a matter of subjectivity versus objectivity. Rather, the deeper issue is one of pluralism, so dear to Nietzsche, and later Bahktin. Derrida (1981) refers to pluralism as polyphony, the proliferation of voices that are not merely the possibility of difference but also the essential necessity of it along with endless dissemination for meaning to exist at all. Identity requires difference. The logical structure of positivistic objectivist absolutism requires not merely the marginalization of different voices. With its narrow absolutist formalism, positivism demands that there can be only one true picture of reality, only one best solution for each problem. Tolerance of the subaltern or alternative perspective is not tolerated.

A necessary condition for the privileging of a single point of view requires the implication of alternative points of view. Objectivity arises only with the realization of subjectivity. Beyond this semiotic fact, the valuation of one perspective over another need not be made permanent. Different perspectives shift in "importance" depending on historical and personal interest. Beginning around the year 1200 AD with the emergent humanist movement when people needed a new secular hero, Aristotle was rehabilitated. The elevation of a piece of information to the status of a relevant fact depends on the goal, need, or interest of the attendant observer.

The possibility of multiple interpretations informing and enriching each other, what Bakhtin (1930/1981) calls the dialogic of heteroglossia, occurs all the time. That is the fundamental synergy of lived experience. Yet, for dialogic to occur, more than one perspective must be allowed. Bahktin, like Nietzsche, dares to reduce science to just another form of literature, a move that enrages those who seek absolute privilege. Heteroglossia, the reading of several different texts in the light of each other, is done all the time by readers of all genre including of course historians. For instance, a description of World War I from the point of view of a homeless orphan may be dramatically different from a description of "the same" historical event from the point of view of a military general, but it is no less "true." Reading them side-by-side changes the meaning of each one. The essence of deconstruction is a tactical discursive move to place at the center of narrative a different point of view. Positivism claims that there is only one true picture of reality thus negating the possibility of dialogue between them. The fact that awards are given in science speaks to its cultural bias for competition and the absolute elimination of "false" pictures of reality.

Positivism presumes not only the possibility but also the necessity of stating issues in such a way that falsifiability will be assured. This is premised on a cultural value, namely efficiency. This penchant for establishing the truth, once and for all, with solution and resolution being finalized, emerged along with industrialization. In the cultural frame of temporal anxiety and the chronic sense of urgency that industrial capitalism spawns, for profit is realized with each unit moved which behooves the profiteer to move as fast as possible, entertaining different perspectives that can give rise to what Roland Barthes calls the ecstasy of reading is simply and unacceptably inefficient. Reading is process oriented. It is thinking. The modern industrial world is goal oriented and demands production which is units produced per unit of time. 
Hence, the modern suspicion of do-nothing intellectual élites, especially in Fascist societies. In such a world, a thing or idea has value only insofar as it can be exploited. Value is a judgment which makes evaluation a subjective process based hopefully (in the interest of justice) on conventional criteria. If a forest cannot be timbered or a river harnessed for generating power, providing water, or fished, then it has no value. It may look pretty but esthetics are mere subjective opinion. However, notice that the objective measure of value in the modern world of positive industrialization, for remember that August Comte and Saint-Simon promoted positivism as the new religion of a specifically industrial world, is ultimately hypertrophic subjectivity. What is valuable in a cost/benefit world is what I personally can exploit or turn to my personal advantage. Rationality itself is reduced to subjective interests in the formulation of cost/benefit calculus. Given what one's desire or goal is, then there is a most efficient, most rational path of action. So long as ethics and morality are deemed irrelevant, then "the given" cannot be assessedonly the path of securing the goal can be measured.

Within historical perspective, which ironically is missing in Bernstein, is the cause of the rise of the emergent split between the subject and the object. It coincides with the emergent sense of spatial thinking and the emerging modern ego (Gebser 1985; Kramer 1997). What is valued as objective truth, is what I want and agree with. Bernstein touches on this as he follows Husserl's (1913/1982) analysis of intersubjectivity in his Ideas Pertaining to a Pure Phenomenology and to a Phenomenological Philosophy, where Husserl picks up on Nietzsche's revolutionary claim that human consciousness as we know it is a product of the need to communicate and is thus an intersubjective phenomenon supported by language (hence, Heidegger's notion of the linguisticality of Dasein). Nietzsche (1882/1974) puts it this way:

I may now proceed to the surmise that consciousness has developed only under the pressure of the need for communication; that from the start it was needed and usefully only between human beings; and that it also developed only in proportion to the degree of this utility. Consciousness is really only a net of communication between human beings. (298)

Here, Nietzsche is picking up where Isocrates left off and initiating the new linguistic turn in the social sciences so prevalent in many scholars, including Ferdinand de Saussure, Edward Sapir, Benjamin Whorf, Martin Heidegger, Ludwig Wittgenstein, Paul Ricoeur, George Lakoff, Jacques Derrida, and so many others. Nietzsche explodes the Cartesian bifurcation of interior subjective knowledge and exterior objective fact. What displaces this old linear notion of causal stimulus acting upon a receptive yet passive psyche is the field of intersubjectivity, which is neither my personal property nor a natural physical object acting upon me.

\section{Discussion}

Bernstein misses important points. To be fair, he is right about knowledge and science not being "absolute." The mind's ability to be aware of its own 
representations makes knowledge and science questionable. Objectivity-that there is some permanent, ahistorical truth, or knowledge framework-is thus false. No single human being will be able to solve all the mysteries of the world through a definite, heuristic, and universal methodology. As we have seen, culture shapes the way we see things and provides us with a definite view of the world. Each culture has its own reality, logic, truth and falsity, and right and wrong. It is all about interpretation, perception, and subjectivity. Basing his argument on the Cartesian tradition, Bernstein claims that subjectivity implies self-awareness, the idea that the human being is aware of his or her inner representations and that his or her mind infers the existence of a thinking subject from such awareness.

What Bernstein calls the immature notion of "objectivity" is what Husserl (1913/ 1982) called the view of the natural attitude, which is the unproven belief that there exists some sort of permanent, ahistorical truth, or knowledge framework in the world "out there." Nietzsche's (1882/1974) thesis of perspectivism is the unavoidable fact that any and all consciousnesses exist in space and time. Hence, consciousness is essentially made of cultural, linguistic, and historical dimensions. Each knowing subject is situated, and this is itself a universal fact. For Nietzsche, as it was (later) for Derrida (1981), a scientific or objectivist picture of the world is only one interpretation among an infinite number of possible interpretations.

The scientific method seems like a powerful tool of knowledge, but it has limitations to its applicability and certainty. The claim that scientific knowledge is absolute does not take other important avenues of human endeavor into account, as well as other ways of discovering knowledge and truth. It also wrongly applies the scientific method which, as great as it is, was never meant to be a cure-all. As it has been described in detail, a scientific method can never be "flawless" because it is designed by humans; it is limited to the present; and it is heuristic and does not deal with the unique. In line with these contentions, not only can repeated observation not ultimately explain induction but also subjectivity may emerge when the variables being measured are intangible. More importantly, there is no method that can see and measure everything because each phenomenon has what Husserl calls a different ontological structure.

The dichotomy between subjectivity and objectivity causes a stir in science, especially the social sciences, as disciplines such as sociology, anthropology, and communication attempt to define an appropriate method, whether it is modeled after a conventional scientific method or something new. We adopt the postmodern view that there well may be an objective reality out there, but au fond, we know that it is our subjective interpretations of it. The issue is not the existence of objective reality. What is problematic is the lack of agreement on whether or not our subjective perceptions correspond with the external world.

Since methods-and, along with them, the data they generate-belong to the realm of subjectivity, then criticism, oftentimes directed to the social sciences, should not be limited to them only but also, and no less, to other sciences too. For future research, investigators should also concentrate more on criticism by emphasizing its weaknesses, by making research assumptions clearer and more delineated, and by showing the utility of important constructs in predicting and understanding other important variables. As Bernstein (1983) claims, there is no 
"single univocal set of criteria for distinguishing what is objective from what is not" (111). Given this, there should be significant discussion about what the criteria should be and how they should be applied. On the same matter of subjectivity, other issues should be addressed for future investigation: "Is subjectivity really the extreme end of relativism?" "Does subjectivity simply mean 'non-objectivity" or does it also come in various shapes and sizes?" or "Can there be a difference between social subjectivity and individual subjectivity?"

Finally, further research should be conducted on the very notion of absolutism. We know that subjectivists are opposed to it, but the word "absolutism" itself never claims that we possess absolute knowledge. Absolutism is just the doctrine that there is only "one truth out there." The very idea of absolute knowledge, made notorious by the philosophers of the enlightenment, has made us change our minds about the a priori meaning of absolutism. Investigators should also concentrate more on the self-vis-à-vis absolutism. To a question such as "Can there be a selfcontained, individuated self who knows the one truth?" (Masterpasqua and Perna 1997), multiple answers are expected to mushroom in future literary circles of the social sciences.

\section{References}

Babbie E (2001) The practice of social research. Wadsworth/Thompson, Belmont

Baker WJ (1991) Positivism versus people: what should psychology be about. In: Tolman CW (ed) Positivism in psychology. Spinger, London

Bakhtin M (1930/1981) The dialogic imagination: four essays. University of Texas Press, Austin

Bernstein RJ (1983) Beyond objectivism and relativism: science, hermeneutics, and praxis. University of Pennsylvania Press, Philadelphia

Bernstein B (1990) The structuring of pedagogic discourse. Routledge, New York

Crotty M (1998) The foundations of social research: meaning and perspective in the research process. Sage Publications, Thousand Oaks

Derrida J (1981) Dissemination. University of Chicago Press, Chicago

Doidge N (2007) The brain that changes itself: stories of personal triumph from the frontiers of brain science. Penguin, New York

Gadamer HG (1989) Truth and method. Crossroad, New York

Gauker C (1995) Thinking out loud. Princeton University Press, Princeton

Gebser J (1985) The ever-present origin. Ohio University Press, Athens

Giles H (1972) The effect of stimulus mildness-broadness in the evaluation of accents. Lang Speech 15:262-269

Guba EG, Lincoln YS (1994) Competing paradigms in qualitative research. In: Denzin NK, Lincoln YS (eds) Handbook of qualitative research. Sage Publications, Thousand Oaks, pp 105-117

Habermas J (1979) Communication and the evolution of society. Beacon, Boston

Hall ET (1966) The hidden dimension. Anchor Books, New York

Hegel GWF (1807/1977) Phenomenology of spirit. Oxford University Press, Oxford

Husserl E (1900/1970) Logical investigations. Routledge, London

Husserl E (1913/1982) Ideas pertaining to a pure phenomenology and to a phenomenological philosophy. Nijhoff, The Hague

Judowitz D (1988) Subjectivity and representation in Descartes: the origins of modernity. Cambridge University Press, Cambridge

Kant I (1785/1981) Groundwork of the metaphysics of morals. Hackett, Indianapolis

Kaplan A (1964) The conduct of inquiry: methodology for behavioral sciences. Chandler, San Francisco 
Kierkegaard S (1997) Concluding unscientific postscript. In: Baird FE, Kaufmann W (eds) From Plato to Nietzsche. Prentice-Hall, Upper Saddle River, pp 1051-1069

Kramer EM (1997) Postmodernism and race. Praeger, Westport

Lakoff G, Johnson M (1999) Philosophy in the flesh: the embodied mind and its challenge to western thought. Basic Books, New York

Lakoff G, Nuñez R (2001) Where mathematics comes from: how the embodied mind brings mathematics into being. Basic Books, New York

Ledoux JE (2002) The synaptic self. Macmillan, New York

Masterpasqua F, Perna PA (1997) The psychological meaning of chaos: translating theory into practice. American Psychological Association, Washington

Merleau-Ponty M (1945/1962) Phenomenology of perception. Humanities Press, New York

Moore JN (1973) How does science work? Am Biol Teach 5:23-26

Nietzsche F (1882/1974) The gay science. Vintage Books, New York

Popper KR (1992) The logic of scientific discovery. Routledge, New York

Rorty R (1998) Truth and progress. Cambridge University Press, Cambridge

Schwartz JM, Begley S (2003) The mind and the brain: Neuroplasticity and the power of mental force. Harper Perennial, New York

Small G, Vorgan G (2008) iBrain: surviving the technological alteration of the modern mind. William Morrow, New York

Weisz P (1965) Elements of biology. McGraw-Hill, New York

Whorf BL (1962) Language, thought and reality: selected writings of Benjamin Lee Whorf. MIT Press, Cambridge

Wittgenstein L (1965) Philosophical investigations. The Macmillan Company, New York 